\title{
Optimal Allocation of Irrigation Water by Balancing Water Use and Food Production
}

\author{
Qin Zhang ${ }^{1}$, Shigeya Maeda ${ }^{2}$ and Toshihiko Kawachi ${ }^{3}$
}

\begin{abstract}
A deterministric optimization model is presented to allocate irrigation waters to blocks of crop fields in an agricultural district. In order to prevent excessive agricultural water use and enhance water productivity, two competing objectives, i.e., minimization of water withdrawal from a river and maximization of crop yield, are formulated. Water balances in a river, a field block and a channel network connecting some field blocks are considered as constraints. Adjusting a weight in a synthesized objective function results in producing a set of noninferior solutions, which can be used to analyze a trade-off between the two objectives. The optimization model is applied to a hypothetical irrigation district for rice production, successfully generating optimal allotments of irrigation waters to blocks of paddy fields and optimal water withdrawals.
\end{abstract}

Keywords: Irrigation water; Optimal allocation; Crop yield; Water management; Paddy field

\section{Introduction}

Water shortage caused by increase in water demand has become serious all over the world. In Japan, obtaining necessary water is sometimes difficult in spite of large amount of precipitation. Although many dams have been constructed for river flow development, this approach is nowadays often criticized because of large investments required and damage to natural environment. Efficient use of water becomes, therefore, important to explore strategies for satisfying water demand without disturbing natural environment significantly.

Water allocation problem in agricultural water management has attracted a growing interest since agriculture is globally a main water-consuming sector. For example, Reca et al. (2001a) developed three optimization models using dynamic programming and linear programming to determine the area for each crop and the amount of irrigation water assigned, and Reca et al. (2001b) applied the models in order to optimize the water allocation plan in Bémbezar irrigation system in Spain. Shangguan et al. (2001) presented a threelevel dynamic programming problem for irrigation scheduling and water allocation to crop and subregions, and operated the models in a semi-arid area, Yangling in China. Evans et al. (2003) demonstrated that current irrigation management based on water rights is neither efficient nor equitable in El Angel watershed in Ecuador, using a linear programming model.

Although these researches mentioned above employ maximization of crop yield or benefit as one of the objectives in the management, saving irrigation water is not thoroughly pursued by setting associated goals. Since percentage of water for domestic use in gross water use tends to increase in

${ }^{1}$ Ph.D. Student, Graduate School of Agricultural Science, Kyoto University, Kitashirakawa-oiwake-cho, Sakyo-ku, Kyoto, 606-8502 Japan

${ }^{2}$ Assistant Professor, Graduate School of Agricultural Science, Kyoto University, Kitashirakawa-oiwake-cho, Sakyo-ku, Kyoto, 606-8502 Japan

${ }^{3}$ Professor, Graduate School of Agricultural Science, Kyoto University, Kitashirakawa-oiwake-cho, Sakyo-ku, Kyoto, 606-8502 Japan
Japan, more efficient water use in agriculture, based on optimal water allocation to crop fields, could be one of the effective strategies to overcome water shortage. In the present study, therefore, a minimum level of necessary water for growing rice is explored while maximizing rice yield by developing a two-objective linear programming model in an irrigation district. The model is applied to a hypothetical irrigation system to demonstrate optimal allocations of irrigation waters.

\section{Optimization model}

An irrigation district which consists of some blocks of crop fields and open channels is considered. Water is withdrawn from a river at several upstream points, and it is conveyed through a network of open channels up to the irrigation blocks. Drained or discharged water from the fields are collected, returning to the downstream part of the river. Irrigated water to a block can be reused for other blocks before it reaches the outlet of the river. An optimal allocation problem of irrigation water to each block in this area can be formulated with two objectives under some constraints using the linear programming method. The first objective is to minimize the amount of water withdrawal from the river for irrigation, while the second objective is to maximize crop yield. These are synthesized into a single objective function, expessed as

$$
\begin{gathered}
\operatorname{minimize}(z=) z_{1}-w z_{2} \\
z_{1}=\sum_{l} Q_{l}^{i r} \\
z_{2}=\sum_{k} A_{k} Y_{k}
\end{gathered}
$$

where $z_{1}$ is the total water withdrawn from the river for irrigation ( $\mathrm{m}^{3} /$ day), $z_{2}$ is the gross crop production obtained in the whole district $(\mathrm{kg}), Q_{l}^{i r}$ is the water withdrawn from the river at a point $l\left(\mathrm{~m}^{3} /\right.$ day $), w$ is the weight, $A_{k}$ is the area of 
the field block $k$, and $Y_{k}$ is the yield function which stands for crop production at a block $k$. In the model, the crop on the fields is assumed to be rice and a linear yield function used for rice is applied. Borrell et al.(1997) conducted regression analysis and derived a linear relationship between the irrigation water in the wet season and the yield of rice. Based on the research, the yield function expressed as (4) is employed in this study under the assumption that the irrigation period in the wet season at the considered district is 120 days.

$$
Y_{k}=171.6 I_{k}-0.465
$$

where $Y_{k}$ stands for the above-ground dry mass of rice on the block $k$ in one season $\left(\mathrm{kg} / \mathrm{m}^{2}\right)$, and $I_{k}$ is the daily-averaged irrigation water for a irrigation block $k$ (m/day). Considering that (4) includes a constant term which is meaningless in the optimization practice, $z_{2}$ in (3) is replaced by

$$
z_{2}=171.6 \sum_{k} A_{k} I_{k}
$$

Eight constraints are taken into account in this allocation problem, expressed as follows:

(i) Continuity of river flow

$$
Q_{e}=Q_{u}-\sum_{l} Q_{l}^{i r}+\sum_{b} Q_{b}^{d}-Q_{\text {out }}+Q_{\text {in }}
$$

where $Q_{e}$ is the discharge at the downstream end of the river ( $\mathrm{m}^{3} /$ day), $Q_{u}$ is the discharge at the upstream end of the river ( $\mathrm{m}^{3} /$ day), $Q_{b}^{d}$ is the discharge returning to river through the channel ( $\mathrm{m}^{3} /$ day), $Q_{\text {out }}$ is the uncontrollable outflow from the river ( $\mathrm{m}^{3} / \mathrm{day}$ ), and $Q_{\text {in }}$ is the uncontrollable inflow into the river $\left(\mathrm{m}^{3} /\right.$ day) .

(ii) Continuity of flow in a channel at a node $i$

If the node $i$ is a junction of channels only, water balance at the node can be written as

$$
\sum_{j=1}^{n_{j}} e(i, j) q_{j 2 i}(i, j)-\sum_{m=1}^{n_{m}} q_{i 2 m}(i, m)=0
$$

where subscripts $j 2 i$ and $i 2 m$ stand for 'inflow to node $i$ ' and 'outflow at node $i$ ', respectively, $j$ is the local number of upstream nodes from which water is transported through channel connected to the node $i$, and $m$ is the local number of downstream nodes linked to the node $i, e(i, j)$ is efficiency of water conveyance in a channel between node $i$ and local node $j(0<e(i, j)<1)$, representing water loss caused by leakage and/or evaporation in the channel, $q_{j 2 i}(i, j)$ is the outflow discharge at the local node $j$ flowing to the node $i$ ( $\mathrm{m}^{3} /$ day), $q_{i 2 m}(i, m)$ is the outflow discharge at the node $i$ in the direction of the local node $m\left(\mathrm{~m}^{3} /\right.$ day $), n_{j}$ is the number of the local nodes $j$ related to the node $i$, and $n_{m}$ is the number of the local nodes $m$ pertaining to the node $i$.

If the node $i$ is a point where irragation water is applied to a block $k$, the following constraint is considered.

$$
\sum_{j=1}^{n_{j}} e(i, j) q_{j 2 i}(i, j)-A_{k} I_{k}=0
$$

where $I_{k}$ is the irrigation water supplied from the node $i$ for the block $k$ (m/day).
Table 1: Area of block of crop field

\begin{tabular}{c|c}
\hline$k$ & $A_{k}\left(\mathrm{~km}^{2}\right)$ \\
\hline 1 & 1.20 \\
2 & 1.30 \\
3 & 0.90 \\
4 & 1.10 \\
5 & 0.80 \\
6 & 1.20 \\
7 & 1.00 \\
\hline
\end{tabular}

If the node $i$ corresponds to a point where water is flowing out from a block $k$, water balance is expressed as

$$
A_{k} D_{k}-\sum_{m=1}^{n_{m}} q_{i 2 m}(i, m)=0
$$

where $D_{k}$ is the water drained from the block $k$, flowing to node $i$ (m/day).

(iii) Continuity of flow at a junction of river and channel

$$
\begin{aligned}
& Q_{l}^{i r}-\sum_{m=1}^{n_{m}} q_{i 2 m}(l, m)=0, \quad \forall l \\
& Q_{b}^{d}-\sum_{j=1}^{n_{j}} q_{j 2 i}(b, j)=0, \quad \forall b
\end{aligned}
$$

(iv) Water balance at an irrigation block $k$

$$
P_{k}-E T_{k}-L_{k}+I_{k}-D_{k}=0, \quad \forall k
$$

where $P_{k}$ is the precipitation at the block $k$ (m/day), $E T_{k}$ stands for the evapotranspiration from the block $k$ (m/day), and $L_{k}$ denotes the deep percolation at the block $k(\mathrm{~m} /$ day). (v) Lower and upper limits of irrigation water at a block $k$

$$
\underline{I_{k}} \leq I_{k} \leq \overline{I_{k}}, \quad \forall k
$$

where $I_{k}$ and $\overline{I_{k}}$ stand for the lower and upper limits of irrigation water withdrawn, respectively ( $\mathrm{m} /$ day).

(vi) Lower limit of river-end discharge

$$
Q_{e} \geq \underline{Q_{e}}
$$

where $\underline{Q}_{e}$ is the lower limit of discharge at the downstream end of the river $\left(\mathrm{m}^{3} /\right.$ day).

(vii) Upper limit of drained water from an irrigation block $k$

$$
D_{k} \leq \overline{D_{k}}, \quad \forall k
$$

where $\overline{D_{k}}$ stands for the upper limit of drained water from the block $k$ (m/day).

(viii) Nonnegative conditions for variables

$$
D_{k}, Q_{l}^{i r}, Q_{b}^{d}, q_{j 2 i}, q_{i 2 m} \geq 0 \quad \forall k, l, b
$$

In the constraints above, $Q_{l}^{i r}$ and $I_{k}$ are decision variables, whereas $Q_{e}, q_{j 2 i}, q_{i 2 m}, Q_{b}^{d}, D_{k}$ are state variables. 

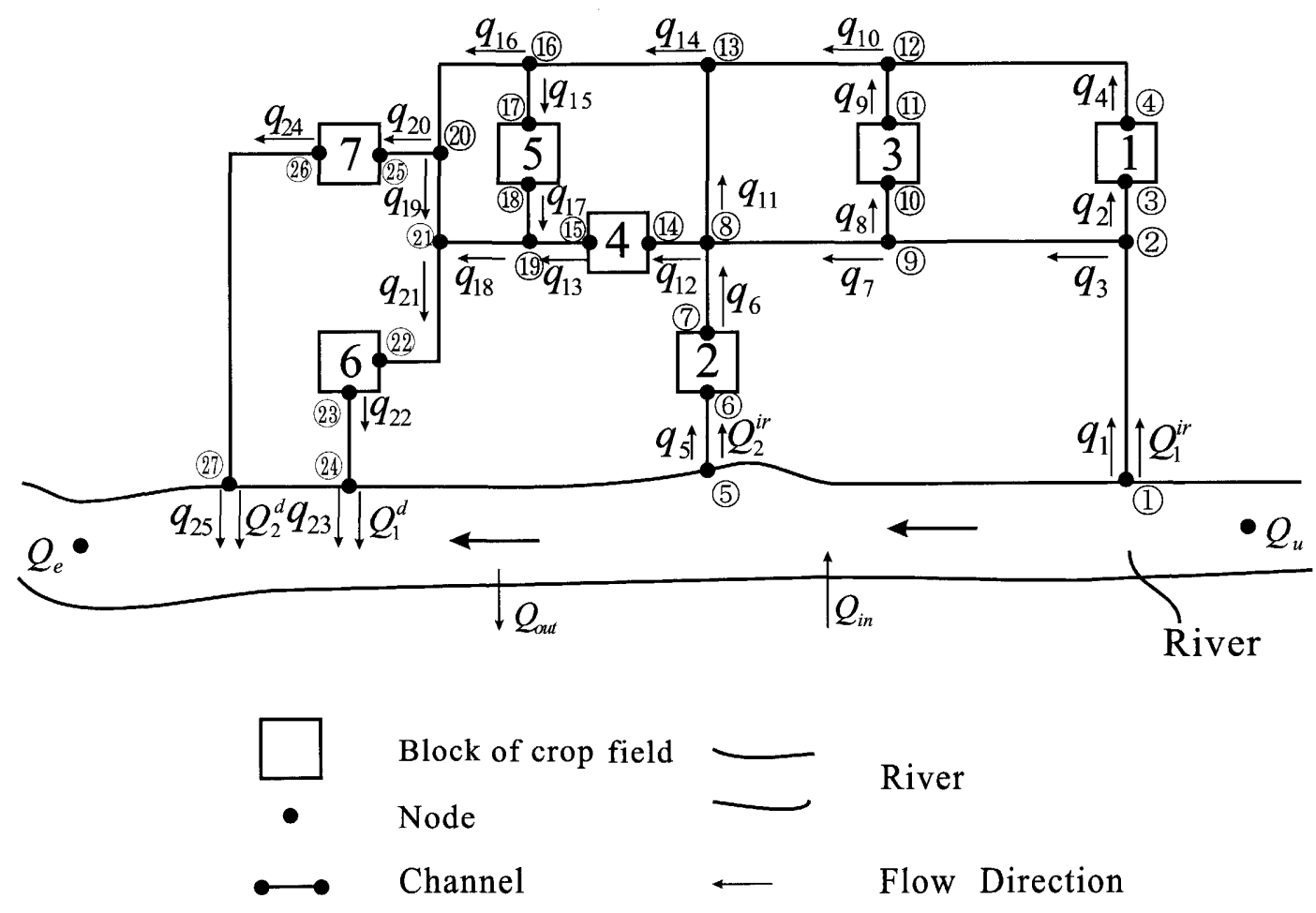

Figure 1: Hypothetical irrigation system

Table 2: Weights and objective values

\begin{tabular}{r|rrrr}
\hline$w$ & $z$ & $z_{1}\left(\mathrm{~m}^{3} /\right.$ day $)$ & $z_{2}(\mathrm{~kg})$ in $(5)$ & Total yield $(\mathrm{kg})$ \\
\hline 100 & $-1,377,019,745.1$ & $70,254.9$ & $13,770,900$ & $10,283,400$ \\
10 & $-137,638,745.1$ & $70,254.9$ & $13,770,900$ & $10,283,400$ \\
1 & $-13,700,645.1$ & $70,254.9$ & $13,770,900$ & $10,283,400$ \\
0.1 & $-1,306,835.1$ & $70,254.9$ & $13,770,900$ & $10,283,400$ \\
0.01 & $-71,381.8$ & $49,977.9$ & $12,136,238$ & $8,648,738$ \\
0.009 & $-59,245.8$ & $49,977.9$ & $12,136,238$ & $8,648,738$ \\
0.008 & $-47,109.9$ & $49,977.9$ & $12,136,238$ & $8,648,738$ \\
0.007 & $-34,973.9$ & $49,977.9$ & $12,136,238$ & $8,648,738$ \\
0.006 & $-22,871.3$ & $49,360.4$ & $12,038,770$ & $8,551,270$ \\
0.005 & $-10,961.0$ & $44,517.3$ & $11,095,828$ & $7,608,328$ \\
0.004 & 133.9 & $44,517.3$ & $11,095,828$ & $7,608,328$ \\
0.003 & $8,988.4$ & $32,120.8$ & $7,711,361$ & $4,223,861$ \\
0.002 & $15,952.0$ & $29,874.8$ & $6,960,096$ & $3,472,596$ \\
0.001 & $22,913.4$ & $29,874.8$ & $6,960,096$ & $3,472,596$ \\
0.0001 & $29,178.6$ & $29,874.8$ & $6,960,096$ & $3,472,596$ \\
0.00001 & $29,805.1$ & $29,874.8$ & $6,960,096$ & $3,472,596$ \\
0.000001 & $29,867.8$ & $29,874.8$ & $6,960,096$ & $3,472,596$ \\
0 & $29,874.8$ & $29,874.8$ & $5,979,917$ & $2,492,417$ \\
\hline
\end{tabular}




\section{Hypothetical irrigation system}

In this research, the model is applied to a hypothetical irrigation system in Japan, shown in Figure 1. In order to simplify the model formulation and computational procedure, a medium-sized hypothetical irrigation district is supposed. In this system, there are two points in the river from which irrigation water can be withdrawn and seven blocks of crop fields need to be irrigated. The number of channels through which the discharge returns to river is 2 . The total number of nodes is 27 , and each nodal number is written in a circle in Figure 1.

The linear equation which relates yield of rice to irrigation water is highly site-specific information. However, such a relation for a Japanese agricultural district has not been obtained, and thus the yield function in (4) is adopted in this computational example. It is certain that a suitable yield function should be created before the optimization model is applied to an actual area.

The value of the constant $Q_{u}-Q_{\text {out }}+Q_{\text {in }}$ is assumed as $3,456,000 \mathrm{~m}^{3} /$ day $\left(=40 \mathrm{~m}^{3} / \mathrm{s}\right)$. The area of each block is asssumed as in Table 1. The efficiency of water conveyance, $e(i, j)$, is assumed 0.9. Precipitation and evapotranspiration within the irrigation season of one year are assumed that: $P_{k}=0.00466 \mathrm{~m} / \mathrm{day} \quad(=1.7 \mathrm{~m} /$ year $), E T_{k}=0.0022 \mathrm{~m} / \mathrm{day}$ $(=0.8 \mathrm{~m} /$ year $)$, respectively. The deep percolation at a block $k, L_{k}$, is assumed $0.005 \mathrm{~m} /$ day.

Since the value of crop yield is not negative, it is supposed that $I_{k}=0.00271 \mathrm{~m} /$ day and $\overline{I_{k}}=0.01070 \mathrm{~m} /$ day based on Borrell et al. (1997). The value of the upper limit of drained water from block $k, \overline{D_{k}}$, is assumed $0.05 \mathrm{~m} / \mathrm{day}$. The lower limit of river flow discharge at the downstream end, $Q_{e}$, is supposed as $2,592,000 \mathrm{~m}^{3} /$ day $\left(=30 \mathrm{~m}^{3} / \mathrm{s}\right)$.

\section{Results and discussions}

The linear programming model applied to the hypothetical irrigation system is solved by the simplex method. Various values are given to the weight, $w$, in (1) in each computation, so that a wide variety of noninferior (or Pareto optimal) solutions can be produced. Table 2 summarizes the objective values in the obtained noninferior soluions associated with varied $w$. Large value of $w$ means that the second objective, i.e., maximizing the total crop yield, is emphasized. In Table 2, it can be confirmed that $z_{2}$ in (5) reaches the upper limit when $w \geq 0.1$. In contrast, setting smaller values to $w$ highlights the first objective, i.e., minimizing the total amount of water withdrawal from the river. Notice that, in Table 2, both values of $z_{1}$ and $z_{2}$ in (5) do not change with $w$ $=0.000001 \sim 0.002$, which means $z_{1}$ reaches its lower limit, $29,874.8 \mathrm{~m}^{3} /$ day $\left(=0.35 \mathrm{~m}^{3} / \mathrm{s}\right)$. A trade-off between the two objectives is depicted in Figure 2. The rice yield increases with the increase of $z_{1}$, as is shown in the figure.

Now two noninferior solutions, $\mathrm{A}$ and $\mathrm{B}$, are investigated. Solutions A and B are obtained with $w=1$ and 0.001 , respectively. Discharges in channels, water withdrawn from the river, return flow discharge, irrigation water and water drained from field blocks in these solutions are listed in Tables $3 \sim 7$, respectively. In Solution A, much water is taken away from the river to supply it to the block of
Table 3: Discharge in channel

\begin{tabular}{r|rr|rr}
\hline & \multicolumn{2}{|c|}{$\mathrm{A}(w=1)$} & \multicolumn{2}{c}{$\mathrm{B}(w=0.001)$} \\
\hline$q_{i}$ & \multicolumn{1}{|c}{$\mathrm{m}^{3} /$ day } & $\mathrm{m}^{3} / \mathrm{s}$ & $\mathrm{m}^{3} /$ day & $\mathrm{m}^{3} / \mathrm{s}$ \\
\hline$q_{1}$ & $54,799.3$ & 0.634 & $14,419.2$ & 0.167 \\
$q_{2}$ & $14,266.7$ & 0.165 & $9,966.2$ & 0.115 \\
$q_{3}$ & $35,052.7$ & 0.406 & $3,011.1$ & 0.035 \\
$q_{4}$ & $9,792.0$ & 0.113 & $5,921.6$ & 0.069 \\
$q_{5}$ & $15,455.6$ & 0.179 & $15,455.6$ & 0.179 \\
$q_{6}$ & $10,608.0$ & 0.123 & $10,608.0$ & 0.123 \\
$q_{7}$ & $20,847.4$ & 0.241 & 0 & 0 \\
$q_{8}$ & $10,700.0$ & 0.124 & $2,710.0$ & 0.031 \\
$q_{9}$ & $7,344.0$ & 0.085 & 153.0 & 0.002 \\
$q_{10}$ & $15,422.4$ & 0.179 & $5,467.1$ & 0.063 \\
$q_{11}$ & $15,232.1$ & 0.176 & $1,637.3$ & 0.019 \\
$q_{12}$ & $13,077.8$ & 0.151 & $7,907.9$ & 0.092 \\
$q_{13}$ & $8,976.0$ & 0.104 & $4,324.9$ & 0.050 \\
$q_{14}$ & $27,589.1$ & 0.319 & $6,394.0$ & 0.074 \\
$q_{15}$ & $9,511.1$ & 0.110 & $2,408.9$ & 0.028 \\
$q_{16}$ & $15,319.0$ & 0.177 & $3,345.7$ & 0.039 \\
$q_{17}$ & $6,528.0$ & 0.076 & 136.0 & 0.002 \\
$q_{18}$ & $13,953.6$ & 0.162 & $4,014.8$ & 0.046 \\
$q_{19}$ & $1,898.3$ & 0.022 & 0 & 0 \\
$q_{20}$ & $11,888.9$ & 0.138 & $3,011.1$ & 0.035 \\
$q_{21}$ & $14,266.7$ & 0.165 & $3,613.3$ & 0.042 \\
$q_{22}$ & $9,792.0$ & 0.113 & 204.0 & 0.002 \\
$q_{23}$ & $8,812.8$ & 0.102 & 183.6 & 0.002 \\
$q_{24}$ & $8,160.0$ & 0.094 & 170.0 & 0.002 \\
$q_{25}$ & $7,344.0$ & 0.085 & 153.0 & 0.002 \\
\hline
\end{tabular}

Table 4: Water withdrawal from river

\begin{tabular}{c|c|c}
\hline & $\mathrm{A}(w=1)$ & $\mathrm{B}(w=0.001)$ \\
\hline$l$ & $Q_{l}^{i r}\left(\mathrm{~m}^{3} / \mathrm{day}\right)$ & $Q_{l}^{i r}\left(\mathrm{~m}^{3} / \mathrm{day}\right)$ \\
\hline 1 & $54,799.3$ & $14,419.2$ \\
2 & $15,455.6$ & $15,455.6$ \\
\hline
\end{tabular}

the fields (Table 4). Thus irrigation waters have the maximum, $0.01070 \mathrm{~m} /$ day in every block (Table 6). Contrary to Solution A, less water circulates through the channels in Solution B (Table 3), and the irrigation water supplied to each block of crop field varies in the range of $0.00271 \sim$ $0.01070 \mathrm{~m} /$ day (Table 6), and thus less water is drained from block $k$, which ranges from 0.00017 to $0.00816 \mathrm{~m} / \mathrm{day}$ (Table 7).

\section{Conclusions}

The multiobjective optimization model was presented to allocate the irrigation water withdrawn from a river to blocks of fields connected by channels in an irrigation district. Two conflicting objectives, i.e., minimizing water use and maximizing crop yield, were considered in the model in order to numerically describe the trade-off between efficient use of water resources and increase of food production. The model was tested by a demonstrative optimization example 


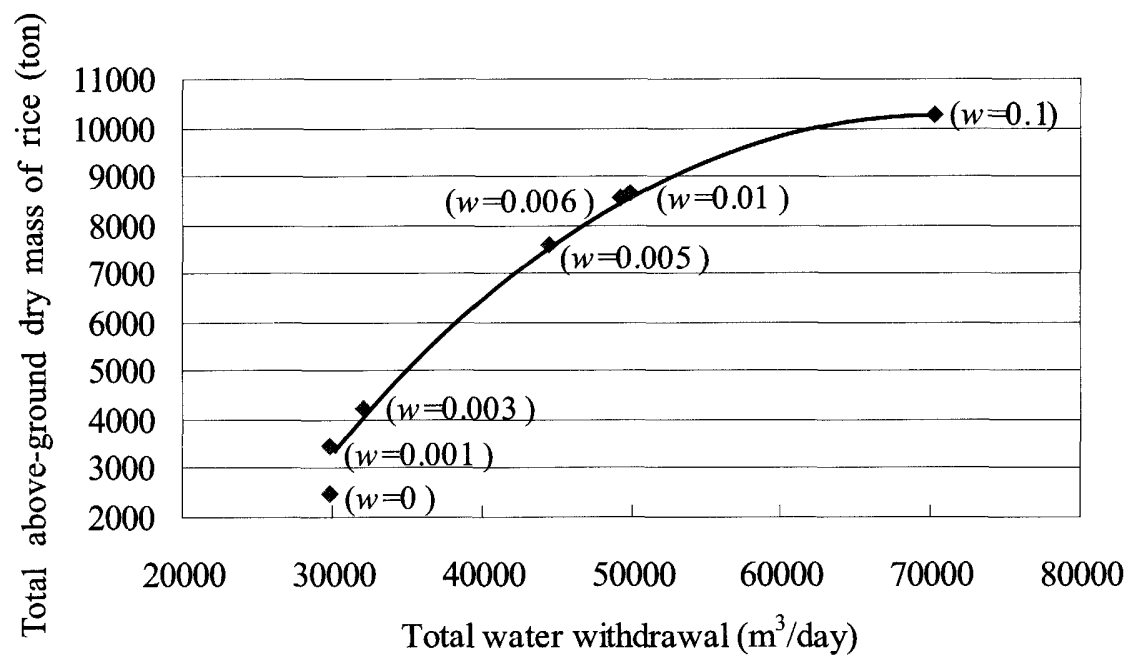

Figure 2: Trade-off between total water withdrawal and total rice yield

Table 5: Discharge returning to river

\begin{tabular}{c|c|c}
\hline & $\mathrm{A}(w=1)$ & $\mathrm{B}(w=0.001)$ \\
\hline$b$ & $Q_{b}^{d}\left(\mathrm{~m}^{3} /\right.$ day $)$ & $Q_{b}^{d}\left(\mathrm{~m}^{3} /\right.$ day $)$ \\
\hline 1 & $8,812.8$ & 183.6 \\
2 & $7,344.0$ & 153.0 \\
\hline
\end{tabular}

Table 6: Irrigation water for block $k$

\begin{tabular}{c|c|c}
\hline & $\mathrm{A}(w=1)$ & $\mathrm{B}(w=0.001)$ \\
\hline$k$ & $I_{k}(\mathrm{~m} / \mathrm{day})$ & $I_{k}(\mathrm{~m} / \mathrm{day})$ \\
\hline 1 & 0.01070 & 0.00747 \\
2 & 0.01070 & 0.01070 \\
3 & 0.01070 & 0.00271 \\
4 & 0.01070 & 0.00647 \\
5 & 0.01070 & 0.00271 \\
6 & 0.01070 & 0.00271 \\
7 & 0.01070 & 0.00271 \\
\hline
\end{tabular}

for a hypothetical irrigation system, where different noninferior solutions (different sets of decision variables) were produced for different weights: attatched to the second objective in the synthesized objective function. Considering not only food production but also minimum water use for agricultural practices, the most desirable allocations for irrigation waters were able to quantitatively produced (as shown in Tables 4, 5 and 6), which differentiates this study from other researches previously conducted. However, further researches are necessary to improve contraints (e.g., water balance in a crop field) and the yield function in order to apply the optimization model to actual irrigation systems. Uncertain change of natural environment such as discharge in the river also needs to be taken into account in the model development.
Table 7: Water drained from block $k$

\begin{tabular}{c|c|c}
\hline & $\mathrm{A}(w=1)$ & $\mathrm{B}(w=0.001)$ \\
\hline$k$ & $D_{k}(\mathrm{~m} /$ day $)$ & $D_{k}(\mathrm{~m} /$ day $)$ \\
\hline 1 & 0.00816 & 0.00493 \\
2 & 0.00816 & 0.00816 \\
3 & 0.00816 & 0.00017 \\
4 & 0.00816 & 0.00393 \\
5 & 0.00816 & 0.00017 \\
6 & 0.00816 & 0.00017 \\
7 & 0.00816 & 0.00017 \\
\hline
\end{tabular}

\section{References}

[1] Borrell, A., Garside, A. and Fukai, S. (1997): Improving efficiency of water use for irrigated rice in a semi-arid tropical environment, Field Crops Research, 52, pp.231-248.

[2] Evans, E. M., Lee, D. R., Boisvert, R. N., Arce, B., Steenhuis, T. S., Prańo, M. and Poats, S.V. (2003): Achieving efficiency and equity in irrigation management: an optimization model of the El Angel watershed, Carchi, Ecuador, Agricultural Systems, 77, pp.1-22.

[3] Reca, J., Roldán, J., Alcaide, M., López, R. and Camacho, E. (2001a): Optimisation model for water allocation in deficit irrigation systems I. Description of the model, Agricultural Water Management, 48, pp.103-116.

[4] Reca, J., Roldán, J., Alcaide, M., López, R. and Camacho, E. (2001b): Optimisation model for water allocation in deficit irrigation systems II. Application to the Bémbezar system, Agricultural Water Management, 48, pp.117-132.

[5] Shangguan, Z., Shao, M., Horton, R., Lei, T., Qin, L. and Ma, J. (2001): A model for regional optimal allocation of irrigation water resources under deficit irrigation and applications, Agricultural Water Management, 52, pp.139-154. 